\title{
Evaluation of Carbon Dioxide Absorption Characteristics Lithium Ortho-Silicate in Chemical Heat Storage
}

\author{
Takehiro Esaki*, Daichi Iwase, Noriyuki Kobayashi \\ Department of Chemical Engineering, Nagoya University, Nagoya, Japan \\ Email: *esaki@energy.gr.jp
}

How to cite this paper: Esaki, T., Iwase, D. and Kobayashi, N. (2017) Evaluation of Carbon Dioxide Absorption Characteristics Lithium Ortho-Silicate in Chemical Heat Storage. Journal of Materials Science and Chemical Engineering, 5, 56-63. https://doi.org/10.4236/msce.2017.54006

Received: January 11, 2017

Accepted: April 27, 2017

Published: April 30, 2017

Copyright $\odot 2017$ by authors and Scientific Research Publishing Inc. This work is licensed under the Creative Commons Attribution International License (CC BY 4.0).

http://creativecommons.org/licenses/by/4.0/

\begin{abstract}
We report the development of technology that may contribute to a reduction in greenhouse gas emissions and improve the energy efficiency of the $\mathrm{CO}_{2}$ capture process. Lithium ortho-silicate is a suitable solid sorbent for capturing $\mathrm{CO}_{2}$. This reversible chemical reaction is also applicable to chemical heat storage. The absorption reaction characteristics of lithium ortho-silicate were studied by a thermogravimetric method and a volumetric method that demonstrated the influence of heat and mass transfer limitations in a packed bed designed to be as small as possible. We developed a method for measuring the absorption reaction characteristics in the experiments. In the experiments, a constant conversion fraction of $60 \%$ was observed. The reaction system was stable to repetition. The $\mathrm{CO}_{2}$ absorption rate depends on the $\mathrm{CO}_{2}$ pressure and reactor temperature. The absorption rate was determined at several reactor temperatures when the conversion fraction was 0.3. In this study, the maximum absorption rate was obtained at $670^{\circ} \mathrm{C}$. It was demonstrated that lithium ortho-silicate is suitable for use in a chemical heat storage system.
\end{abstract}

\section{Keywords}

$\mathrm{CO}_{2}$ Capture, Chemical Heat Storage, Lithium Ortho-Silicate, Absorption Rate

\section{Introduction}

Recently the global issue of climate change has received ever increasing attention, with the development of methods for reduction of $\mathrm{CO}_{2}$ emissions from industrial processes being one of the main focuses. The process with the potential to make a significant impact on emissions is carbon capture and storage (CCS). The $\mathrm{CO}_{2}$ separation process accounts for $\sim 60 \%$ of the energy consumption 
within the CCS process [1] [2] [3]. In $\mathrm{CO}_{2}$ separation technology, zeolite, aminebased materials, magnesium and calcium oxides, and lithium-based oxide sorbents have been developed. In particular, lithium ortho-silicate has potential for $\mathrm{CO}_{2}$ capture capacity, and desorbs at a lower temperature than with $\mathrm{MgO}$ and $\mathrm{CaO}$ [4] [5]. The lithium ortho-silicate reaction formula is as follow:

$$
\mathrm{Li}_{4} \mathrm{SiO}_{4}[\mathrm{~s}]+\mathrm{CO}_{2}[\mathrm{~g}] \leftrightarrow \mathrm{Li}_{2} \mathrm{SiO}_{3}[\mathrm{~s}]+\mathrm{Li}_{2} \mathrm{CO}_{3}[\mathrm{~s}]
$$

Figure 1 shows a schematic of the equilibrium line for the lithium ortho-silicate and $\mathrm{CO}_{2}$ reaction system. In this system, when lithium ortho-silicate absorbs $\mathrm{CO}_{2}$, lithium carbonate $\left(\mathrm{Li}_{2} \mathrm{CO}_{3}\right)$ and lithium silicate $\left(\mathrm{Li}_{2} \mathrm{SiO}_{3}\right)$ are generated with heat release at a high temperature, correlating to the $\mathrm{CO}_{2}$ pressure [6]. When heat at high temperature is supplied to lithium carbonate and lithium silicate, lithium ortho-silicate is recovered by $\mathrm{CO}_{2}$ desorption.

In this study, we suggest a heat storage technology with the lithium ortho-silicate reaction system. Since $\mathrm{CO}_{2}$ is used as refrigerant, a direct heat storage system can be operated. $\mathrm{CO}_{2}$ gas is separated from the exhaust gas from industrial processes, and reaction heat at high temperature is supplied to the process. In the desorption step, exhaust heat is supplied to the reactant, and $\mathrm{CO}_{2}$ gas is captured. This technology potentially contributes to a reduction in greenhouse gas emissions and an improvement of energy efficiency for the process. In this paper, the absorption reaction characteristics of the lithium ortho-silicate and $\mathrm{CO}_{2}$ reaction system have been investigated. We evaluated the effect of the absorption and desorption cycle repetitions on the conversion fraction with a thermogravimetric method, as well as the effect of the absorption temperature and pressure on absorption rate.

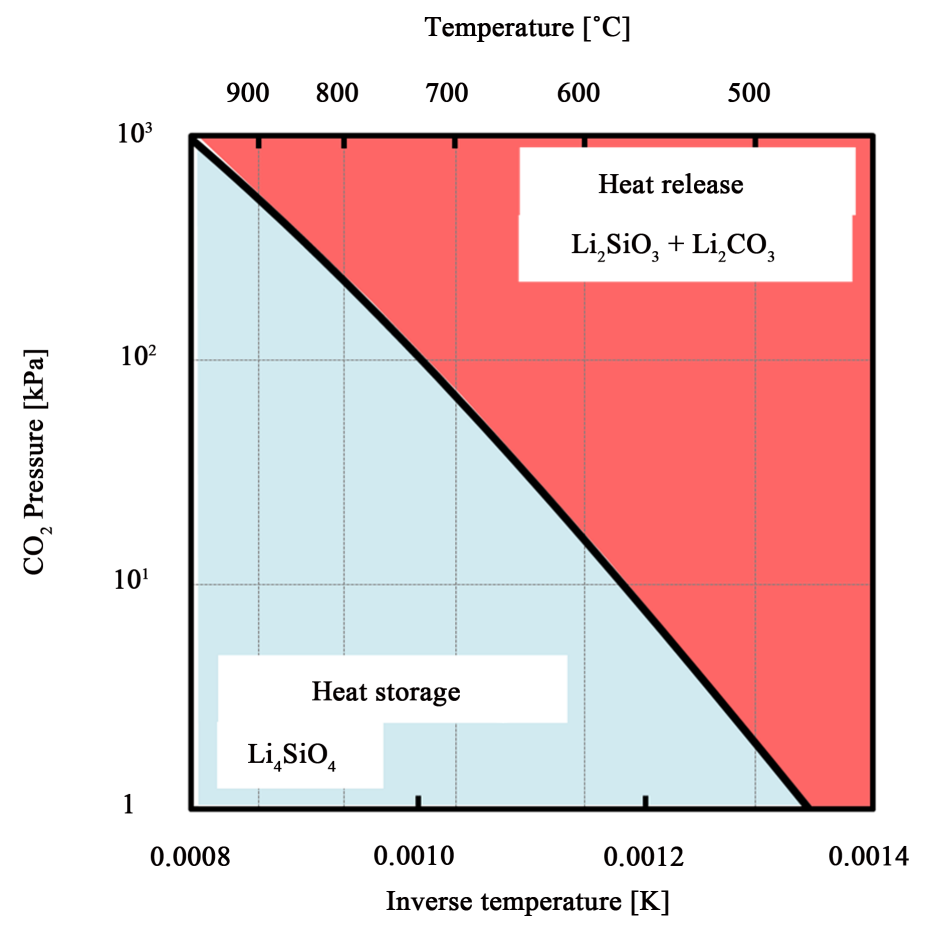

Figure 1. Equilibrium pressure and temperature diagram for lithium ortho-silicate. 


\section{Repetitive Durability of $\mathrm{Li}_{4} \mathrm{SiO}_{4}$}

\subsection{Experimental Procedure}

Lithium ortho-silicate made by Kanto Kagaku was selected for this study. In this experiment, the sample diameter was under $5 \mu \mathrm{m}$. Before the experiment, a reactant sample was out gassed at $500^{\circ} \mathrm{C}$ for $10 \mathrm{~h}$ under vacuum.

This experiment for the evaluation of repetition durability for the reaction at which it absorbs is measured using a thermogravimetric method Figure 2 shows a schematic diagram of the experimental apparatus. $10 \mathrm{mg}$ of the lithium orthosilicate reactant was used, and the packed bed thickness was less than $1 \mathrm{~mm}$. In the absorption step, $\mathrm{CO}_{2}$ gas was introduced to the reactant sample at $100 \mathrm{kPa}$ and $700^{\circ} \mathrm{C}$. After the absorption step, the temperature of the reactant sample was changed to $800^{\circ} \mathrm{C}$ in the desorption step. When the weight change reached equilibrium, we calculated the amount of $\mathrm{CO}_{2}$ used in the absorption/desorption reaction from the quantity of gas represented by the weight change. The reversible absorption/desorption reaction could be repeated 20 times. We evaluated the effect of absorption and desorption repetition cycles on the conversion fraction.

\subsection{Experimental Results and Discussions}

Figure 3 shows the experimental results. The weight of the reactant sample increased with absorption, and decreased with desorption. Figure 4 shows the reaction characteristics on repeating the cycle 20 times. From the results, the conversion fraction was decreased after the initial five repetitions. After the fifth cycle, the conversion fraction remained constant at $60 \%$. It was observed that the reactant particles were sintered and the reactant packed bed contracted at high temperatures. The $\mathrm{CO}_{2}$ diffusion resistance in the packed bed gradually increased. After 5 cycles, the reactant sintering converged. The expansion and contraction of the packed bed for the $\mathrm{CO}_{2}$ reaction was stable. The experiment demonstrates that the lithium ortho-silicate and $\mathrm{CO}_{2}$ reaction system can be repeatedly utilized in chemical heat storage technology.

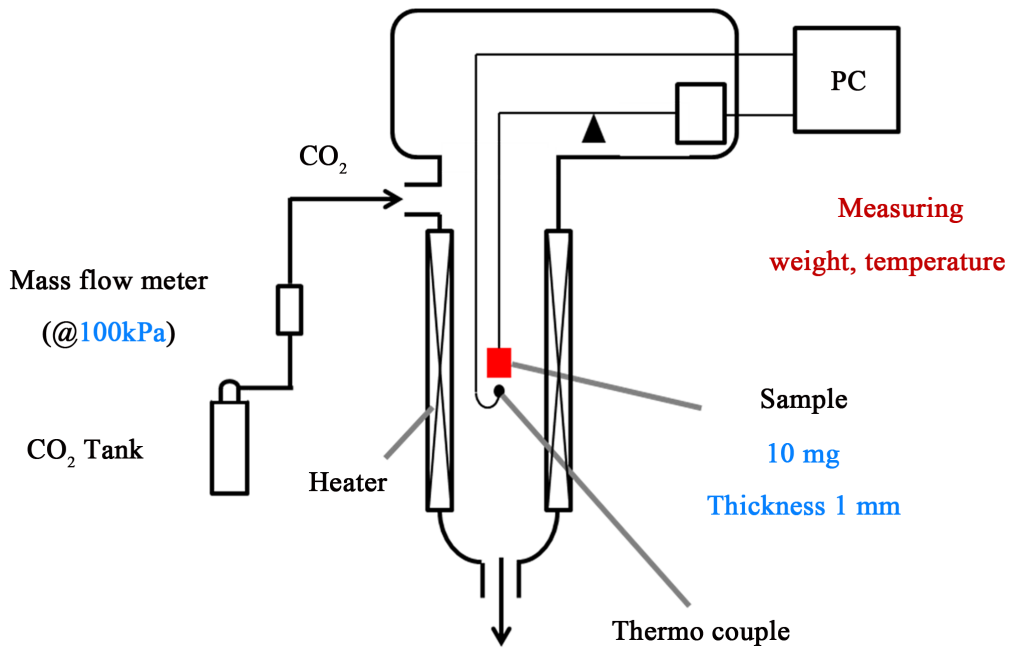

Figure 2. Experimental apparatus in thermogravimetric method. 


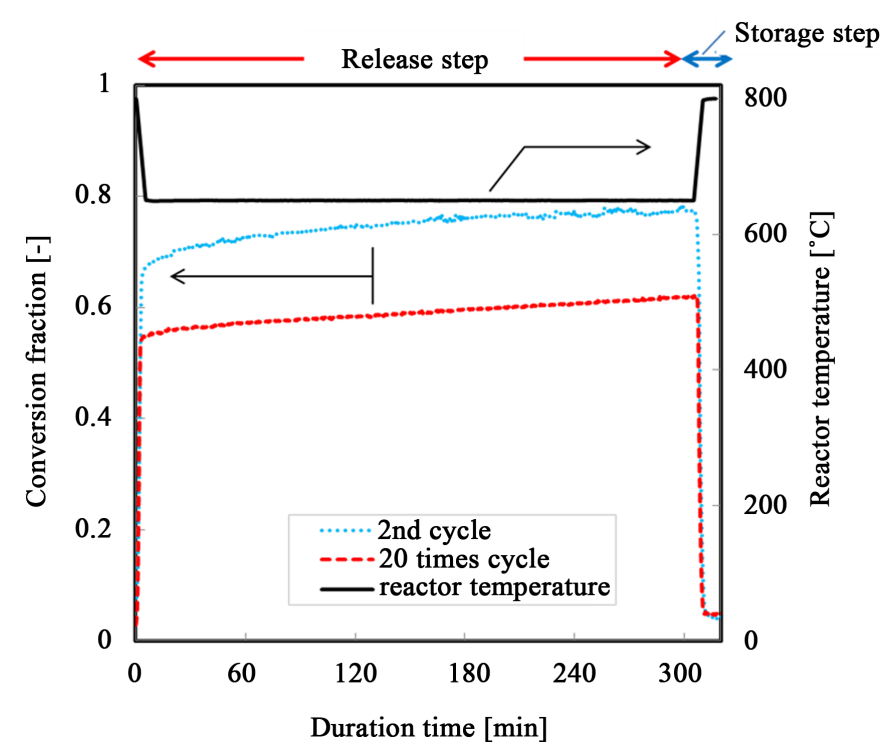

Figure 3. Typical time variation of conversion fraction.

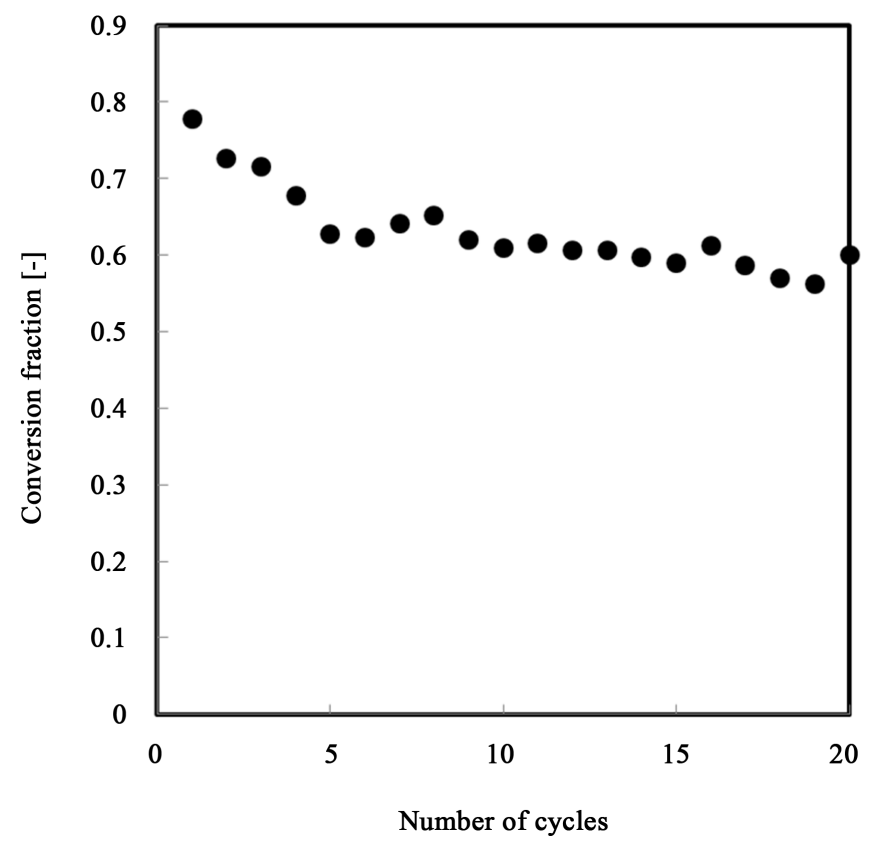

Figure 4. Changes in conversion fraction from 0 to 20 times repeated reaction.

\section{Absorption Rate Characteristics of $\mathrm{Li}_{4} \mathrm{SiO}_{4}$}

\subsection{Experimental Procedure}

The experimental apparatus for measuring the absorption rate is shown in Figure 5. This equipment consisted of a $\mathrm{CO}_{2}$ tank, reactor, and vacuum pump. The reactor and the connecting pipe lines were maintained at a specific temperature by a thermos reactor heater. A Pt resistance thermocouple and pressure gauge were connected to a $\mathrm{CO}_{2}$ tank, and the $\mathrm{CO}_{2}$ gas and pressure was measured. The inner volumes of the $\mathrm{CO}_{2}$ tank and reactor were $2.0 \mathrm{~L}$ and $50 \mathrm{~mL}$, respectively. The weight of reactant sample was $0.1 \mathrm{~g}$. 


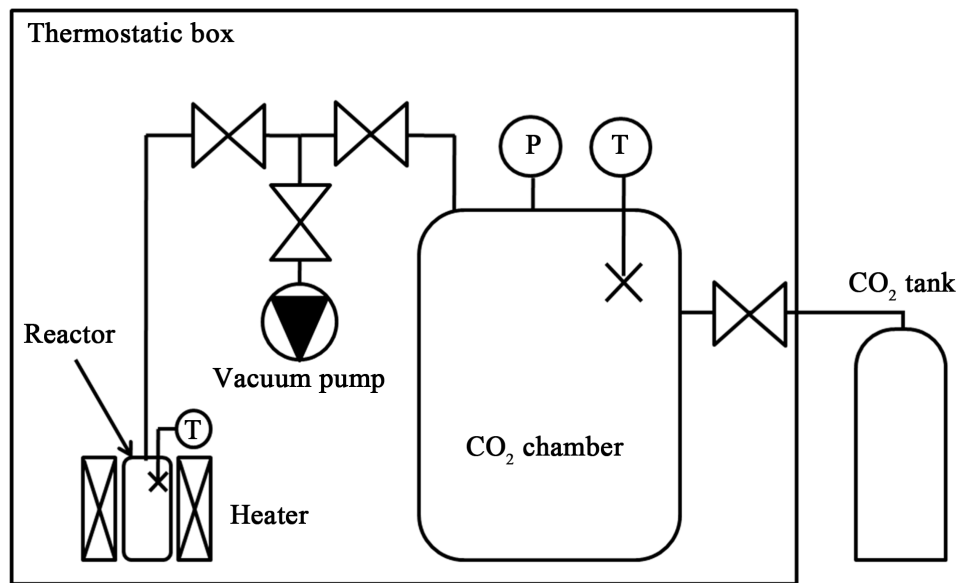

Figure 5. Experimental apparatus in volumetric method.

When the reactor was connected to the $\mathrm{CO}_{2}$ tank, the tank pressure decreased with progress of the $\mathrm{CO}_{2}$ absorption reaction. We calculated the amount of $\mathrm{CO}_{2}$ used in the absorption reaction from the quantity of gas causing the pressure change. In this method, the tank and weight of lithium ortho-silicate sample was adjusted in order to keep the tank pressure change under 5\%. After the absorption reaction step, the temperature of the reactor was raised and the $\mathrm{CO}_{2}$ gas was desorbed. The conversion fraction was defined by

$$
\begin{gathered}
\Delta n_{\text {absorption }}=n_{\text {initial }}-n_{\text {tank }}=\frac{\Delta P_{\text {tank }} \cdot V_{\text {tank }}}{R_{g} T_{\text {tank }}} \\
X_{\text {conversion }}=\Delta n_{\text {absorption }} / \Delta n_{\text {theory }}
\end{gathered}
$$

In these experiments, we evaluated the effect of reaction temperature and pressure on absorption rate.

\subsection{Experimental Results and Discussions}

Figure 6 shows the absorption rate as the conversion fraction approached 0.3 . The experimental result shows the effect of $\mathrm{CO}_{2}$ pressure on the absorption rate. In this experiment, the reactor temperature was maintained at $630^{\circ} \mathrm{C}$. The $\mathrm{CO}_{2}$ pressure was set at $30,60,90$, and $100 \mathrm{kPa}$. From the results, the same absorption rates were observed at 60,90 and $100 \mathrm{kPa}$. The absorption rate was lower at 30 $\mathrm{kPa}$ compared with the other pressure conditions. The equilibrium pressure was $27.2 \mathrm{kPa}$ when the reactor temperature was $630^{\circ} \mathrm{C}$. The change in $\mathrm{CO}_{2}$ pressure at $30 \mathrm{kPa}$ was very small. Therefore, the driving force for the absorption reaction was small. It is estimated that the pressure difference of $2.8 \mathrm{kPa}$ was a significant influence on the absorption rate.

Figure 7 shows the effect of reactor temperature on the absorption rate. In this experiment, the $\mathrm{CO}_{2}$ pressure was set $100 \mathrm{kPa}$. The reactor temperature was set $500,550,610,630,650,670$ and $700^{\circ} \mathrm{C}$. From the results, when the reactor temperature was high the absorption rate was large. It is revealed that the absorption rate was affected by the reactor temperature. It is estimated that this reaction system could be utilized to heat output at high temperature. The ab- 


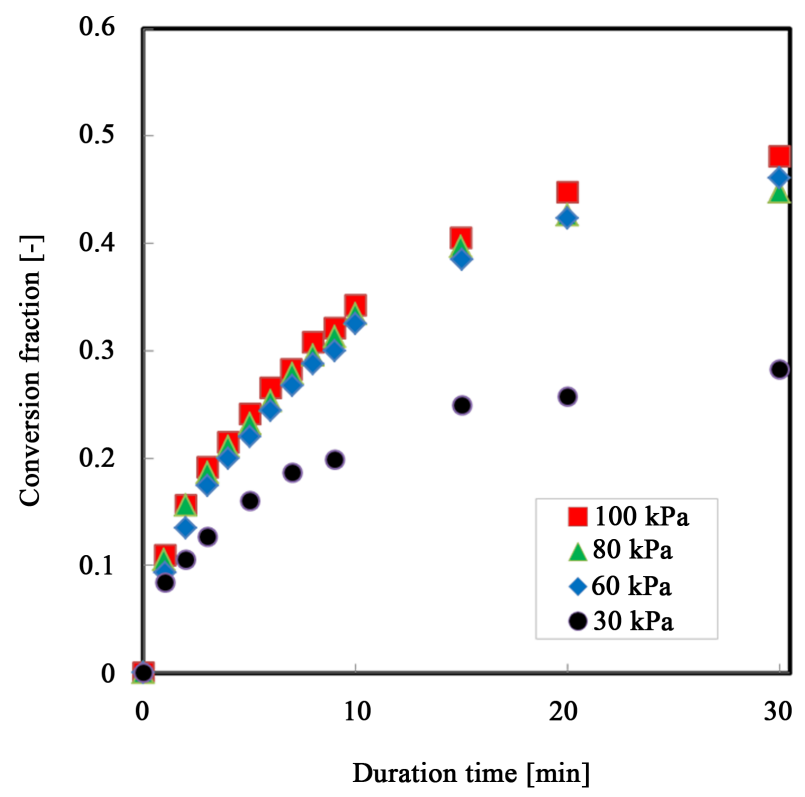

Figure 6. Typical time variation of the conversion fraction for different $\mathrm{CO}_{2}$ pressure.

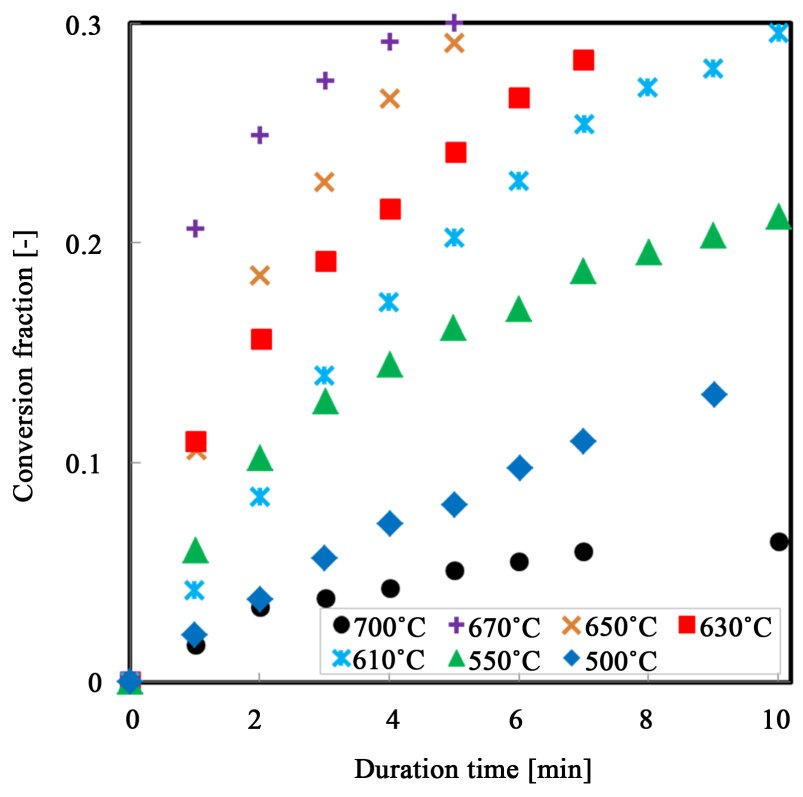

Figure 7. Typical time variation of the conversion fraction for different reactor temperature.

sorption rate was extremely small at $700^{\circ} \mathrm{C}$. This is why the difference of equilibrium temperature was small. Figure 8 shows the absorption rate value on each reactor temperature at a conversion fraction of 0.3 . The maximum absorption rate was obtained at $670^{\circ} \mathrm{C}$ in this experiment.

Figure 9 shows photos of reactant sample packed beds before and after the experiment. After the experiment, the reactant sample packed bed was sintered and contracted. It is estimated that the $\mathrm{CO}_{2}$ diffusion rate in the packed bed decreased as the porosity of the packed bed decreased. In future, we plan to develop composite materials for a more stable configuration of reactant. 


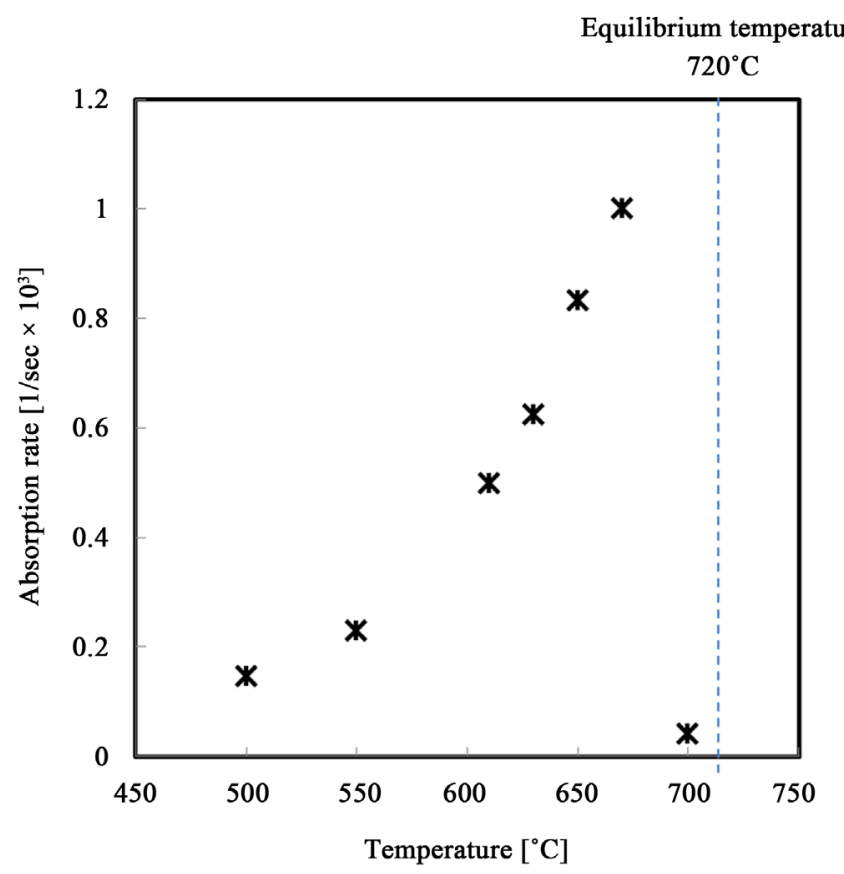

Figure 8. Absorption rate at each reactor temperature.
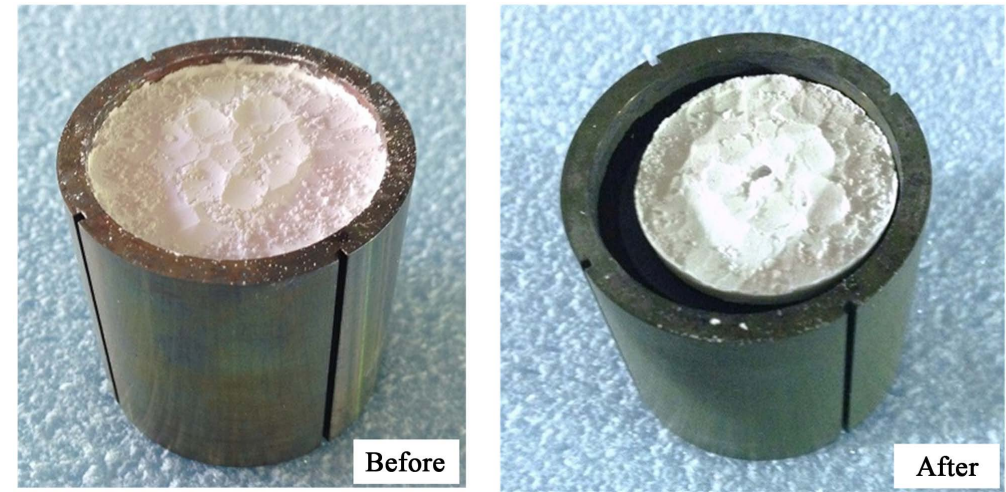

Figure 9. Photo of the lithium ortho-silicate packed beds appearance.

\section{Conclusions}

In this study, the reaction characteristics of lithium ortho-silicate were evaluated. From the experimental study, we obtained the following results.

1) The reversible reaction of lithium ortho-silicate and $\mathrm{CO}_{2}$ could be repeated 20 times. The $60 \%$ conversion fraction was stable and consistent. The lithium ortho-silicate reaction system could be utilized with repetition for chemical heat storage.

2) The absorption rate was increased as the reactor and pressure were increased. However, the absorption rate decreased significantly under high pressure conditions because the difference between the equilibrium states was small.

\section{References}

[1] Viebahn, P., Nitsch, J., Fischedick, M., Esken, A., Schüwer, D., Supersberger, N., Zuberbühler, U. and Edenhofer, O. (2007) Comparison of Carbon Capture and 
Storage with Renewable Energy Technologies Regarding Structural, Economic, and Ecological Aspects in Germany. International Journal of Greenhouse Gas Control, 1, 121-133. https://doi.org/10.1016/S1750-5836(07)00024-2

[2] Figueroa, J.D., Fout, T., Plasynski, S., McIlvried, H. and Srivastava, R.D. (2008) Advances in $\mathrm{CO}_{2}$ Capture Technology-The U.S. Department of Energy's Carbon Sequestration Program. International Journal of Greenhouse Gas Control, 2, 9-20. https://doi.org/10.1016/S1750-5836(07)00094-1

[3] Bounaceur, R., Lape, N., Roizard, D., Vallieres, C. and Favre, E. (2006) Membrane Processes for Post-Combustion Carbon Dioxide Capture: A Parametric Study. Energy, 31, 2556-2570. https://doi.org/10.1016/j.energy.2005.10.038

[4] Jeoung, Lee, J.H., Kim, H.Y. and Moon, H.R. (2016) Effects of Porous Carbon Additives on the $\mathrm{CO}_{2}$ Absorption Performance of Lithium Orthosilicate. Thermochimica Acta, 637, 31-37. https://doi.org/10.1016/j.tca.2016.05.010

[5] Zhang, S., Zhang, Q., Wang, H.Y., Ni, Y.H. and Zhu, Z.B. (2014) Absorption Behaviors Study on Doped $\mathrm{Li}_{4} \mathrm{SiO}_{4}$ under a Humidified Atmosphere with Low $\mathrm{CO}_{2}$ Concentration. International Journal of Hydrogen Energy, 39, 17913-17920. https://doi.org/10.1016/j.ijhydene.2014.07.011

[6] Kanki, K., Maki, H. and Mizuhata, M. (2016) Carbon Dioxide Absorption Behavior of Surface-Modified Lithium Orthosilicate/Potassium Carbonate Prepared by Ball Milling. International Journal of Hydrogen Energy, 41, 18893-18899. https://doi.org/10.1016/j.ijhydene.2016.06.158

Submit or recommend next manuscript to SCIRP and we will provide best service for you:

Accepting pre-submission inquiries through Email, Facebook, LinkedIn, Twitter, etc. A wide selection of journals (inclusive of 9 subjects, more than 200 journals) Providing 24-hour high-quality service User-friendly online submission system Fair and swift peer-review system Efficient typesetting and proofreading procedure Display of the result of downloads and visits, as well as the number of cited articles Maximum dissemination of your research work

Submit your manuscript at: http://papersubmission.scirp.org/

Or contact msce@scirp.org 